\title{
LA GENERACIÓN DEL MEDIO SIGLO: EN BUSCA DEL ESPÍRITU BURGUÉS
}

Jesús Antonio Bejarano*

U no de los tantos ingenios que tuvo nuestro siglo xIX acuñó una frase que estuvo a punto de volverse memorable: después de la Gran Colombia, dijo, Venezuela se convirtió en un cuartel, Ecuador en un convento y Colombia en una universidad. Era una manera de decir que estábamos culturalmente engrandecidos solo con relación a la indigencia de los demás.

En esta época, en la que hasta las cosas cuotidianas acostumbraban a decirse en un latín que, según Zea, el prócer, "no conoció la edad de Cicerón y hacía reír a los sabios de Europa”, hubo de todo: los poetas jugaban a la melancolía sin sentirla de veras; los prosistas de costumbres encontraban en las pequeñas cosas anónimas y en los aconteceres humildes el signo de la autenticidad nacional y asignaban de golpe dimensiones históricas al bambuco y a las matas de geranio; los filósofos, con más audacia que inteligencia, interpretaban sin recato las corrientes europeas. Era la edad de oro.

Sin Acrópolis ni Partenón, "La Atenas Suramericana”, hipérbole piadosa con que Menéndez y Pelayo tuvo el gusto de complacernos, sirvió para identificarnos ante Europa y ante el resto de la inculta América Latina. La generación del medio siglo -y las que le siguieron después- creyó ver en ello la definición que mejor le correspondía, sin percatarse de la desmesura. Un francés, Pierre D’Espagnat, no dejó de advertirlo:

E1 colombiano -escribió- es orador, la frase sale galante, con vida propia,

llena de movimiento y garbo, la fluidez, la abundancia (son) inimitables; su-

* Prólogo a Escritos sobre economía y política, de Salvador Camacho Roldán, Bogotá, Colcultura, 1976. Fecha de recepción: 23-08-2016, fecha de aceptación: 20-10-2016. Sugerencia de citación: Bejarano, J. A. "La generación del medio siglo: en busca del espíritu burgués", Revista de Economía Institucional 18, 35, 2016, pp. 293-300. DoI: http://dx.doi.org/10.18601/01245996.v18n35.15. 
ben, se ciernen en las alturas de la elocuencia [...] y después de varias horas uno se pregunta qué han dicho [...] audacia peligrosa para un pueblo joven y pequeño es la de aceptar, descartada la posibilidad de que en ello haya la menor malicia, la herencia cargada de gloria, el mote más soberbio y difícil de sustentar; el de sucesor de la divina Atenas.

La imagen grandilocuente y en cierto modo auténtica que los hombres del medio siglo se empeñaban en mantener a través del incesante ejercicio de la escritura (y en la que esta generación creía expresar su compromiso histórico) era mucho más que el entusiasmo de una ilusión de pronto recobrada. Los años que van de la Independencia hasta la mitad del siglo son una larga espera no exenta de convulsiones. De la Independencia se esperaba un orden nuevo que los burócratas y comerciantes, esperanzados en él, no veían nacer. La inestabilidad política, la aún patente gravitación del ejército en la vida política del país, la prosperidad económica que demoraba su llegada y las mal disimuladas apetencias de poder de las castas bajas, hacían pensar incluso en la emancipación como un estruendoso fracaso. La barbarización del estilo político, la indefinición política del Estado y la presencia de una casta militar que defendía por la fuerza la legitimidad política conquistada durante la guerra, eran hasta entonces los resultados más palpables de la Independencia.

El espíritu científico, que mal o bien había emergido en los años anteriores a la guerra, hubo de retroceder ante preocupaciones sociales y políticas más perentorias. Las minorías cultas, ocupadas en los avatares de la política, apenas si produjeron una que otra crónica mediocre. La teoría política se vio oscurecida por el sentido pragmático del juego del poder, en el que importaban menos los propósitos sociales y políticos del poder que la presencia de los caudillos en él.

El panorama era sombrío, ciertamente, y, sin embargo, estos tenían en sus manos una República en la que lo único bien definido era su espacio geográfico. Sin códigos precisos, con instituciones sociales deshechas por la guerra, y con un pasado al que no se quería apelar porque se le rechazaba del todo, no era fácil formarle un espíritu a la República recién nacida y más difícil aún, cuando una economía poco menos que inexistente impedía, de una parte, la cabal comprensión de la naturaleza del Estado, y de otra, la concreción, en una expresión política, de los intereses de clase y del papel de los grupos sociales en el nuevo orden republicano.

Es, pues, apenas comprensible el entusiasmo con que se reciben las transformaciones económicas del medio siglo. El año 1848 presencia cambios rápidos en todos los órdenes: la economía encontraba en las exportaciones una salida al desconcertante estancamiento de 
las tres décadas anteriores; el despertar de las tendencias sociales que comienzan a asumir expresiones políticas precisas gracias al deslinde de clases que produce la expansión económica, junto con la súbita revelación de la importancia del Estado por lo que él significa como instrumento de poder para una clase, son el inmediato resultado del orden económico que empieza a surgir.

La conciencia del cambio, posiblemente más fuerte que el cambio mismo, era más rica en contenidos simbólicos que en transformaciones materiales. El cambio era vivido por la clase en el poder como su transformación de criolla en burguesa. Crearse para sí, afanosamente, una conciencia burguesa y un estilo de vida burgués sería la tarea cultural de la generación del medio siglo. Sin embargo, la tarea de esta emergente clase de terratenientes convertidos (por obra de las circunstancias) en burócratas y comerciantes iba a encontrar un límite casi infranqueable tanto en la precaria riqueza material como en la indigencia espiritual a la que ineludiblemente los sometía un pasado de colonizados. Era esta, por cierto, una burguesía solo a medias, pobre en medios y pobre en espíritu. Jamás hubo en Colombia los niveles de acumulación que se presenciaron en Perú, Chile o Bolivia: "La diferencia entre dicha élite y la burguesía europea -escribe Safford refiriéndose a los burgueses de entonces-consistía en que los colombianos eran muy pobres". Descendientes de burócratas coloniales de segundo orden los unos, de "orejones sabaneros" recién enriquecidos, los otros; económicamente engrandecidos los más a costa de la riqueza pública o, a lo sumo, herederos de hacendados coloniales empobrecidos por la guerra, imitaban falsamente los gustos de Europa sin poder sostener los niveles de consumo europeos. Mientras en Inglaterra la cerveza encontraba sus más entusiastas consumidores entre la servidumbre de cocina, aquí Castillo y Rada, en la creencia de que la inclinación por ella era una debilidad aristocrática, no ocultaba el orgullo de exhibiría.

Un visitante inglés, Hamilton, retrata bien la excesiva anglomanía del consumo:

Un extranjero después de su llegada se sorprendió de encontrar en las calles
a una hermosa mujer muy bien vestida, fumando tabaco con la mayor des-
preocupación; aun cuando la dama tenía un lindo sombrero colocado coque-
tamente a un lado de la cabeza, con un hermoso collar de perlas, los dedos
llenos de anillos, una bata de seda negra adornada con numerosos abalorios
cubriendo su esbelta figura, su sorpresa fue todavía mayor al mirar hacia abajo
y descubrir que estaba sin zapatos ni medias.

Embebidos en la imitación de los gustos europeos superpuestos a los modos de vida coloniales, los nuevos consumidores disimulaban mal la representación patética de lo cursi. 
En el orden del espíritu las cosas no eran mejores. E1 pasado terrateniente, que no podían negar aunque se empeñaran en ello, determinaba el alcance de sus reflexiones.

Descendientes de una clase sin tradición aristocrática, de hacendados que no pensaron nada porque ideológicamente nada tenían que legitimar, carecían por entero de un pasado intelectual que sirviera de soporte a sus actitudes culturales.

Sobre un terreno tan precario, la generación del medio siglo hubo de encarar la tarea de legitimar, en el plano de la teoría, sus propias ambiciones. No debe sorprender que, en ese intento de justificar un orden que instauraron ellos mismos, en el que no siempre era fácil distinguir entre el propósito histórico de los pronunciamientos del político y los más mezquinos intereses del comerciante, la influencia ideológica de Europa hubiera tenido un carácter ante todo verbal. Era más una influencia que se admitía para poder creer más que para poder pensar. Se trataba, en efecto, más de justificarse que de comprender una realidad cuyo rumbo ellos mismos habían fijado de antemano. Sería menos sorprendente aún si se pensara que tales delimitaciones ideológicas debían producirse a la sombra de los generales, halagando en ellos una vanidad casi siempre superior a su capacidad de comprender el sentido de las transformaciones que se estaban sucediendo. De cualquier modo, supieron enseñarles cómo se pasa a la historia a despecho de sus escasos méritos.

La tarea, emprendida con entusiasmo y sin sentido alguno de las limitaciones que le eran inherentes, fue vasta: era menester, primero, construirle un espíritu civil a la nueva República; segundo, elaborar una ética para sí mismos, es decir, una concepción burguesa de la vida, y, finalmente, aunque políticamente no menos importante, desde el estudio de la historia enfrentar el pasado y eliminar sus residuos tanto para su beneficio como para poder creer (y hacer creer al pueblo raso) que su tiempo era mejor que la herencia bochornosa que habían dejado atrás.

Los vigilantes de la formación del espíritu republicano debieron ver por sobre todo la gravitación de la casta militar en la vida política nacional. Si la guerra había dejado al aparato estatal en manos de los militares, ya era tiempo de que se diera cabida a los sectores políticos emergentes, y ello por dos razones: la primera, porque solo mediante un orden institucional fundado en el respeto a la Constitución era factible conservar, así fuera precariamente, la estabilidad política, y la segunda, porque solo tal estabilidad garantizaba el camino a la prosperidad económica. Camacho Roldán no dejó de advertirlo en 
la exposición que, como acusador a nombre de la República en el proceso contra Obando, hizo ante el Senado:

E1 poder militar que sobrevivió a las encarnizadas luchas de independencia, poder organizado en medio de individualidades disueltas, poder armado en medio de un pueblo desarmado, fuerza viva y latente al lado de gobiernos sin vigor y de poblaciones esparcidas sobre un vasto territorio, no podía menos de ser amenazante a la tranquilidad pública y a la nueva organización que, pasada la guerra con la metrópoli, exigía una República pobre y atrasada.

En el plano práctico se postulaba la eliminación del ejército permanente, y en el político una democratización, a la postre puramente formal, de las bases del poder político, es decir, una República fundada sobre el poder civil. No habrá de extrañarnos el apego total a las teorías sobre el Estado liberal cuya práctica decaía en Europa. Llamados al ejercicio del poder civil, que solo conocían de oídas porque jamás lo habían practicado, aquellos sectores políticos emergentes hubieron de recurrir, más por inexperiencia que por falta de imaginación, a lo primero que se les ofrecía. Puestos de acuerdo sobre su parte práctica, no lo estuvieron en sus fundamentos teóricos. Rápidamente fue visible "un piélago de ideologías en que se combinaban por partes iguales el utilitarismo de Bentham y el utopismo de Fourier, el individualismo anarquista de Proudhon y el liberalismo ecléctico de Spencer con las ideas de La Enciclopedia y las más extrañas doctrinas espiritistas, deístas y evolucionistas", según expresión de Jaramillo Uribe.

Si algún mérito puede concederse a esta generación, no es precisamente el de haber elaborado una teoría jurídica; el utilitarismo, que según los entendidos es el menos filosófico de los sistemas, bastó a los hombres de esta generación para llevar al Estado un sistema de normas jurídicas de una asombrosa simplicidad, para remplazar lo que García del Río denominaba "la barbarie de la legislación española". Lo que hay de meritorio en ello es haber percibido la necesidad histórica de esta sustitución y haberla adelantado sin demasiadas complicaciones.

También el utilitarismo hubo de servirles para elaborar una concepción de la vida burguesa. En el remplazo de don Quijote por el homo œconomicus - para apelar de nuevo a la acertada expresión de Jaramillo Uribe- se iría a encontrar el desplazamiento de una concepción nobiliaria de la vida, que se tuvo por pura imitación, por otra en la cual se imponía la conciencia de que el trabajo y el patrimonio eran títulos suficientes para adquirir derechos y hasta para tener un papel dirigente en la sociedad. Quizá más en esto que en el terreno del saber se revelaba la "anglomanía" en todo su significado: lo inglés se convertía para ellos en el ideal de la virtud burguesa. La fe en el progreso del país (es decir, en el de ellos mismos), en la libertad, en 
la justicia, en el laissez faire y en las leyes naturales son una manera de dotar a la indocta minoría dirigente de una clara conciencia de sus objetivos.

Camacho Roldán comprendió, mejor que ninguno de sus contemporáneos, la particularidad de estas inquietudes. Supo captar, bajo el espíritu de hombre práctico del que carecieron (o que al menos no supieron reflejar) la mayoría de los hombres de su época, las necesidades propias del progreso material. Poco menos que desconocido como prosista, burócrata de segundo orden durante la mayor parte de su vida pública, figura casi sin importancia en el acontecer político nacional, tuvo sin embargo el mérito de ser el único verdaderamente obsesionado por las condiciones del progreso económico, preocupación que supo expresar sin recurrir a las complicaciones teóricas propias del verbo de su tiempo. Mientras José María Samper se ocupaba del orden institucional a través de la elaboración de una teoría que sustentara los principios constitucionales del Estado burgués, mientras Miguel Samper aclaraba en qué consistía el liberalismo que todos pregonaban pero muy pocos entendían, mientras Murillo Toro y Florentino González legitimaban las reformas con la economía clásica, Camacho Roldán se ocupaba de las cosas menudas y menos ostentosas, pero de las cuales, en último término, dependía de manera concreta el progreso nacional. Sin pretensiones, supo enseñarles a sus contemporáneos el camino de las transformaciones materiales: se ocupó del desarrollo del comercio, del porvenir de las manufacturas, de los caminos y los ferrocarriles, de la colonización, de los problemas monetarios y fiscales, de la deuda pública, del comercio exterior, en fin, de todas aquellas cuestiones que no admitían el brillo de las grandes elucubraciones, pero sin las cuales esta generación no hubiera podido concretar sus aspiraciones de burguesa.

La evaluación de la herencia española sería la última tarea de esta generación del medio siglo. Aquí, como en casi todo, el radicalismo pudo más que el análisis riguroso del pasado. Mientras la intelectualidad burguesa de Europa apelaba a la historia para prolongar el pasado de Occidente, para pensarse históricamente como naciones y saber qué eran, para constatar las regularidades del acontecer histórico y descubrir en ellas el sentido progresivo de la vida social, entre nosotros la historia se convirtió en una tarea que llamaron patriótica, en un afán que tenía más de afirmación de sí mismos que de búsqueda intelectual. La evaluación de la herencia española que realizan Ospina, Samper, García del Río o Camacho Roldán intentaba solamente poner al desnudo el contrasentido, histórico del régimen 
colonial español, para significar con ello que su mundo era el mejor de los mundos posibles.

Esta imagen radical de la economía colonial, impuesta hasta hace muy poco en las academias, sorprende por su candidez: sus impulsores se limitaron a afirmar, simplemente, que la Colonia no fue lo que ellos habrían deseado, es decir, librecambista. De allí nació toda una tradición historiográfica que, combinada pomposamente con héroes que jamás lo fueron (pero cuyas hazañas se cantaron en el Himno Nacional), contribuyó a formar la imagen grandilocuente con la que hasta hace poco se alimentaron nuestros historiadores. Loable por sus propósitos políticos pero carente de todo rigor, la versión histórica que elaboraron decía más de ellos mismos que de la sociedad colonial. Indicaba más, en efecto, cómo pensaban en su propio tiempo acerca de un pasado que con entusiasmo abandonaban definitivamente.

Se entenderán así las obsesiones y los méritos de esta generación. Fueron eruditos en la medida de sus posibilidades y de las circunstancias intelectuales en que les tocó vivir. A la sombra de tantos laureles de sabio que las generaciones posteriores les atribuyeron, nacieron y se desarrollaron concepciones políticas que, aunque mal sustentadas teóricamente, en la práctica fueron realistas y en ocasiones afortunadas. Fueron, ante todo, y ese es su verdadero mérito, hombres políticamente prácticos que, sin embargo, no se reconocían como tales porque admiraban la pompa de las ideas.

Quienquiera que se aventure en la lectura de la obra de Camacho Roldán advertirá enseguida el espíritu que la anima y la distancia que establece con la del resto de sus contemporáneos. El historiador encontrará en ella el transcurso de los problemas económicos de la segunda mitad del siglo xIx, pero no meditaciones en torno a los grandes problemas de la cultura o de la teoría política. Sus escritos, casi todos fruto de consideraciones inmediatas sobre la circunstancia cotidiana (con excepción quizá de sus Memorias), ponen al descubierto el espíritu de quien no ocultó detrás del verbo lo que de verdad era: un comerciante. No elaboró teorías ni sentó doctrina. No tuvo, en suma, lo que el historiador de las ideas llamaría un pensamiento, es decir, una concepción coherente e ideológicamente ordenada del mundo que le correspondió vivir. Incluso en sus escritos políticos, terreno en el que por entonces nadie dejaba escapar la oportunidad para brillantes elucubraciones, se observa un ánimo más modesto y una preocupación por las consecuencias prácticas del acontecimiento político. Dijo de sí mismo: "Doy lo que puedo dar y no estoy obligado a más”, queriendo indicar con ello su carencia de pretensiones en el 
orden de la cultura. Se ocupó solo, en efecto, de señalar el camino de la prosperidad burguesa.

Quienes han querido ver en la cultura política del siglo XIx la manifestación de auténticas cogitaciones cuando en verdad no fue más que un festival provinciano de malas abstracciones, han dejado curiosamente en el olvido al único prosista verdaderamente auténtico de su tiempo. Quizá porque Camacho Roldán, aunque liberal, no se enredó en la discusión sobre los adjetivos que mejor correspondían a un sustantivo cuya existencia no estaba del todo resuelta, quizá porque no se preocupó demasiado de saber si la República debía ser liberal o lo que fuera, sino solo de enseñar la necesidad de que fuese ante todo República, es decir, definida por la solidez de su base económica antes que por la teoría subyacente en sus instituciones, nuestros historiadores han reconocido en él apenas un político de segundo orden. Rescatar, pues, lo que hay de auténtico en su obra es el propósito de esta selección. 